\title{
IoT based Automatic Damaged Street Light Fault Detection Management System
}

\author{
Ashok Kumar Nanduri ${ }^{1}$, Siva Kumar Kotamraju ${ }^{2}$, G L Sravanthi ${ }^{3}$, Sadhu Ratna Babu ${ }^{4}$, K V K V L Pavan Kumar $^{5}$ \\ Department of Computer Science and Engineering, Vignan's Nirula Institute of Technology and Science for Women \\ Pedapalakaluru, Guntur-522009, Andhra Pradesh, India ${ }^{1,2,3}$ \\ Department of Information Technology, Bapatla Engineering College, GBC Rd, Mahatmajipuram \\ Bapatla-522102, Andhra Pradesh, India ${ }^{4}$ \\ Department of Electronics and Communication Engineering, Koneru Lakshmaiah Education Foundation \\ Vaddeswaram, Guntur-522502, Andhra Pradesh, India
}

\begin{abstract}
The IoT (Internet of Things) is a blooming technology that mainly concentrates on the interconnection of devices or components to one another and the people. As the time being, many of these connections are changing as "Device Device" from "Human to Device". Finding the faulty street light automatically is become a vital milestone by using this technology. The primary goal of the project is to provide control and identification of the damaged street light automatically. The lighting system which targets the energy and automatic operation on economical affordable for the streets and immediate information response about the street light fault. In general, the damage of the street light is observed by getting the complaints from the colony (street) people. Whereas in this proposed work using sensors these lights working status is easily captured without any manual interaction. So that it reduces manual efforts and the delay to fix problems. So, to reduce such problem we come with the solution wherein automatic detection of street light issues i.e.; whether the street light is working or not will be found at night time and it should send the notification to the authorized person if there is a problem in particular streetlight and also the location of the place where the streetlight is damaged. The street lights are automatically ON/OFF using IoT. In this system, it checks whether the street light is ON/ OFF. The LDR sensor will ON/OFF the street lights automatically, based on the condition of the weather.
\end{abstract}

Keywords-IoT (Internet of Things); GSM (Global System for Mobile); LDR (Light Dependent Resistor); LED (Light-Emitting Diode); GPS (Global Positioning System); Raspberry; Twilio

\section{INTRODUCTION}

An important and essential role is being played by the Internet of Things in every one's regular life. There is a clear increase in the changes being made among the traditional systems, \& other general household components and traditional systems for making a better life [1 to 6]. The major problem of the available system of electricity is the issue of connectivity because of the major connections is manually handled by several contractors. Manually, the settings of the timer are done. Additionally, the timer needs 12 hours' of power supply continuously, setting the timer may interrupt in the loss of power supply continuously [7]. IoT is characterized through largely shared, original world smaller things, and the capability of processing and with the storage of restriction that contains the presentation, confidentiality, consistency, and safety [8].
Pervasive devices are linked using IoT and many networks are convenient for delivering protected and effectual provisions for entire applications anywhere and anytime [9]. The Internet of Technology is combined with IT (Information Technology) and OT (Operational Technology) in which the unstructured data generated by machines are studied for making improvements. According to the research work of $\mathrm{Li} \mathrm{Da} \mathrm{Zu}$ et al. [10], D. Giusto et al. [11] and Saifuzzaman et al. [12] IoT is combining of physical devices with sensors, electronics, and software using the internet, which allows the objects to fetch and interchange the data through the ecosystem. It is determined as IoT because all the components described here are utilized in making a better ecosystem. As it is already known that one of the major assets of the city's is street light which provides road safety and increases the security in city centers and houses too. There are many automation applications of IoT such as smart roads, smart parking, smart lighting, smart home, and many more. In the existing system that is the manual system of street lighting contains many issues like connectivity problems, maintenance problems, and the timing issue. These issues will be solved using the technology of IoT [13]. This system depends on the smart and climatic flexibility of street lighting, management automatically [14]. Several issues are simplified by automation in the economy of the world and regular life [15]. Currently, the system of streetlight flexibility is majorly challenged. Controlling the distant area location is a major dilemma. Human mistakes lead to wastage of energy and the system's low performance [16]. Based on the survey conducted by $\mathrm{S}$. K. Cho et.al. [17], it is determined that 30 percent of electricity is consumed by street lights in each city. Currently, the street lights are will be in ON state before the sunset and they get OFF after getting light in the atmosphere, sometimes the light will be in ON state whole day. As it is our responsibility to save energy, we need to take initiative in saving energy. Our project yields the best solution for electricity wastage. Automatic ON/OFF of the street light is an effective solution that will decrease the consumption of the lights of the streets up to 20 percent when the environment contains light.

\section{RELATED WORK}

PLC usage in Automated street lighting, usage of PLC in street light handling is a wonderful concept by the XD26 PLC controller [17]. Manual work is not necessary for this system. 
LDR plays an important role in changing the state as ON/OFF automatically, as a result of the sunlight. The benefits of this method are seasonal variations effect, growth in the efficiency of energy, less cost for operating and maintenance. Crouzet Millennium software involvement in this project helps in testing and analytics with the exact function of streetlights.

In [18], Street light observing and controlling system is an automated system based on GSM, helps in amplifying the effectiveness and precision of an organization by providing the change in the street lights automatically in schedules, the 2 fundamental modules are client-side and the server-side. The microcontroller is the additional connection to GSM modern of client-side whereas the server-side is made of Java-based web server. Building and implementing the future evolution through implanted systems to save the power of the street light system is the main aim of the street light controlling system automatically using the help of a microcontroller. Nowadays, human life became so busy that there's no time to switch off unnecessary lights.

The best remedy for this expenditure of electric power is described in this paper. Moreover, manual work is abolished completely. LDR (Light Dependent Resistor) and photoelectric sensors are the 2 sensors utilized to identify either light or dark time and to find out the movement on the street respectively. The street lighting system can be controlled using the microcontroller PIC16F877A acts as if the brain, where usage of programming language to execute the software of the microcontroller using the language of $C$ [19].

A new path of diminished power, usage was proposed using the approach of RFID based on GSM for the automatic street light system. The reduction in recovering power failure time can be done by this system [20]. Through this GSM street light, load maintenance and also any complaints regarding power could be warned. Power could be saved by the electric department by adopting this system. This system also moves ahead to minimize the time during the processing of all new connections of power suggestions with the help of RFID.

Automatic street lights project motto is just to control the utility of power on the streets, abolish manual work. In this aspect, the street light circuits consisted of particular sensors, LDR, and microcontrollers the whole day. LDR, sensors, and microcontrollers are the 3 basic components required LDR helps in consistently maintaining the streetlight off during daytime as there is no requirement until there is a low light point or low frequency of streetlights thereby the LDR consists of high resistance [20-22]. This stops the power supply to the transistor's base. Finally, the lights of the street will not be glowing.

During most of the night, Intelligent street lighting systems utilizing GSM, street light systems of conventional in regions with less incidence of passersby are online without any cause. The result of this is the bulk of power is wasted unnecessarily. Street lighting systems became reality because of the vast accessibility of flexible technology of lighting such as the wireless connection of the internet, light-emitting diode lamp, well-grounded functionality, power conservation, and quick reacting. This main theme of this study is to describe that the Intelligent street lighting ISL system was the initial to achieve the command for the public systems of lighting in a flexible way. Building and implementing the future evolution through implanted systems to save the power of the street light system is the main aim of the street light controlling system automatically using the help of a microcontroller. Nowadays, human life became so busy that there's no time to switch off unnecessary lights. The best remedy for this expenditure of electric power is described in this paper. Moreover, manual work is abolished completely. LDR (Light Dependent Resistor) and photoelectric sensors are the 2 sensors utilized to identify either light or dark time and to find out the movement on the street respectively. The street lighting system can be controlled using the microcontroller PIC16F877A acts as if the brain, where usage of programming language to execute the software of the microcontroller using the language of $\mathrm{C}$.

\section{PROPOSED Work}

In the research of the damaged Street Light identification System, we will identify the reduction in power consumption. According to our modern lifestyle energy is the basic requirement for both developing and developed countries. For better understanding, we build a prototype for street lighting to find the effectiveness of our system.

This research work covers all reviews from various sources, which targets different concepts of street light systems and risks of human effort. In this work, we discuss two important concepts and get unique results effectively. The proper operation of the system of street lighting by the addition of other systems will help us to develop a research work which is easy and also consumes less power and cost, which can be accessed by the internet. The driver architecture of LED is everywhere to design a street light system in a smart way, which is reliable and reduces energy waste. They undoubtedly describe the automatic ON/OFF of the lights automatically. Later, Morais et al. and Silva et.al studied about the dimming concepts of light according to IEEE.

2017 R10-HTC (Region 10 Humanitarian Technology Conference), 2017 21-23 December, Dhaka which is the capital of Bangladesh 122 large amount of energy is saved by making the ON/OFF of the street light depended on the object movement by the help of modules (IR modules have been used in this). They increased the intensity of the lamp when the object moves under that light region, which helped in the reduction of power consumption. In the same way, in this project we used the LDR concept to detect the light condition, GPS is used to fetch the exact location, and LED is used to indicate the damaged light. The GPS module contains the data in the raw format; it contains several data in different forms. In this paper, the latitude, and longitude of the region where the light is damaged need to be found. Now the series of data is modified in terms of latitude and longitude; using these easily access the location. Each street light connects with an LDR and a LED. In this, the red-colored LED has been used, which specifies danger in general. Relays are used for connecting with lights. The variation of the lights OFF because of the power loss and damage is known by setting threshold value. Whenever the threshold value coincides, treat it as power loss. If the threshold value does not match it specifies the fault of light in large volume. The cloud storage system monitors 
continuously anywhere and anytime. Internet is used to monitor the entire system and all information will be saved in the database for future purposes. The whole system is designed using the concept of IoT as all kinds of sensors, software, cloud, and hardware are combined to make the system effectively. A smart city is one of the booming concepts. Therefore, this work will take one of the initiatives in developing a smart city.

To describe the utility, effectiveness of the entire system, we need to design an architecture that can be used to view the whole functionality in a look as shown in Fig. 1. The architecture, simply says that the entire system can be classified into two parts. The initial part is the operation of street lights and the other is sending information to the authorized person.

Here we use RaspberryPi program for controlling the street light and to detect the fault using the storage system of cloud. The lights of the street are operated manually in general.

Raspberry pi program is utilized for the street lights controlling and the detection of a fault in them through the storage system of the cloud. Present, manually the lights of streets are operated. The control of the street lights and the detection of a fault in them is done through the storage system of the cloud. It checks the ON/OFF of the street lights, and the faulty in the lamps identified. The ON/OFF of the street lights done after checking the weather condition. For checking the weather condition the LDR is used. The LDR (Light Dependent Resistor) checks the condition of weather is light/dark, dark indicates no light, and light indicates the presence of light. If the LDR results in light from the lamp, then consider it as the time of day with light. It is considered as the time of night while it receives results as dark from the LDR. Then the system permits the Switch ON the lamps of the street.

Now the lamps of the street are in ON state. And few lights are in OFF state due to the fault in them. And the system identifies that there is a fault in the lamps, they are not glowing. The lights of the street are not glowing because of some failure; this is known through the LDR. The LDR is inversely proportional to the intensity of light. Now the red LED attached to that street lamp will start glowing. And a message will send to the respective ward member or authorized person. The message includes the message of damage along with the URL.

The URL specifies the exact location of the faulty light. The location of the damaged light is known by GPS. This message will send from the account of Twilio. In the Twilio account, we will specify the contact details of the ward member.

At any point in time, the status of the system will be known anytime, anywhere as we are using the storage system of the cloud. As the lights of the streets are connected to the account of Twilio through the storage system of the cloud. The data of the sensor is stored in the system of the cloud using the account of Twilio. Therefore, the data of the street lights can be accessed easily from the storage of the cloud.

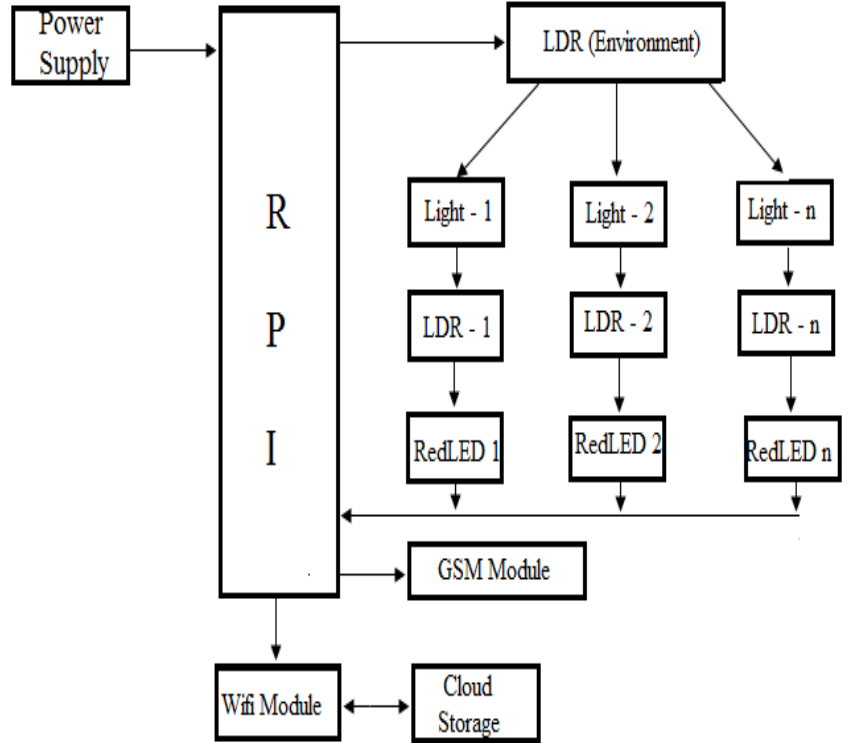

Fig. 1. Architecture for Automatic Street Light Damage Detection.

\section{A. System Design}

- To design an environment that uses IoT in real-time to determine the controlling of the system of street light and testing the working performance of the application.

- The sensor of ambient lights is used to find the intensity experimentally and using that intensity appropriate action of control is taken on the lights.

- To build a library of many modules that replicates the conditional parameters of the network.

- To prepare a GUI (graphical User Interface) and to check the light's status.

If the research work compared with the Automatic street light system, this system saves energy up to 8 percent to 10 percent as it works only on sunrise and set timings. This system even works with the weather condition, which also saves manual effort during winter seasons. The exact location of the damaged light identified easily, whenever there is a fault in the light quickly alert message to the respective authorized person. So that the person can know about the fault and can respond to it. It also reduces the human effort of reporting. The message includes the complaint of the light and the exact location is sending in the form URL. On selecting the URL, this location will get displayed. The system will continue monitoring at all locations through the system of the cloud.

Fig. 2 describes the entire flow of the system. Initially, the LDR checks whether the light of the atmosphere is ON/OFF. No action is performed if it is in the ON state. If the weather's state is OFF, then automatically the light of the street will become ON. If there is any fault in the lamps of the street the red LED attach to each street light, will be ON. Here the color red indicates the damage. 


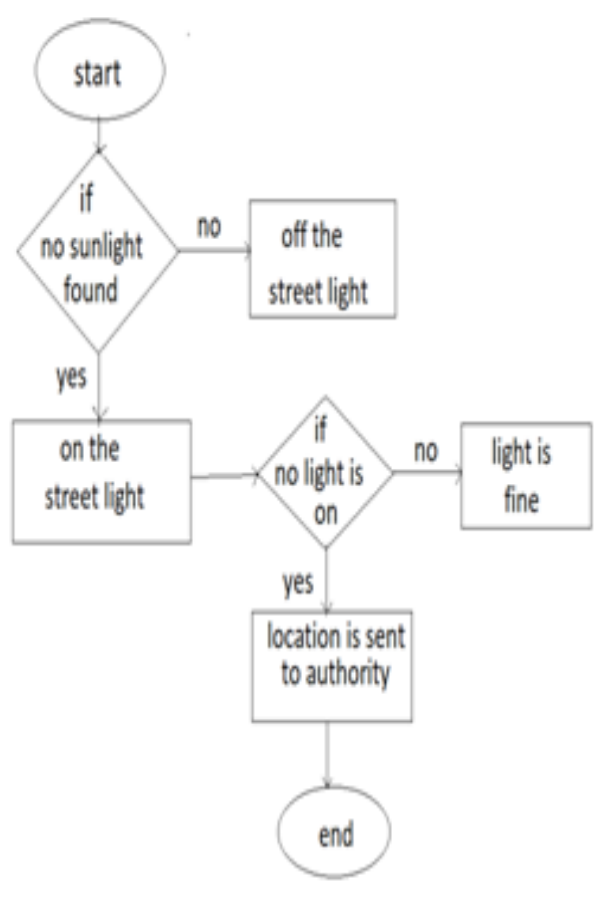

Fig. 2. Data Flow Diagram for Damaged Street Light Process.

Each street light contains their respective LDR and red LED, this LDR is used to sense the street light and ON the red LED automatically, in case of a faulty lamp. The location will send to the authorized person through the Twilio account. The Twilio Account is cloud storage, which stores the data. The description of the message and the mobile number of the authorized person is attached to this. At the time of fault detection, this message will send to that person. The exact location will be fetched through the GPS. These contains several forms of data, but in our project, we are using Bluetooth data which consists of longitude and latitude of the faulty light. After fixing the damaged lamp, the red LED will get OFF automatically.

\section{RESUlt AND Discussion}

Initially, we design a prototype to estimate the arranging process of the whole system and can be done as part of future research, development. After completion of the entire work, we design a proposed system as displayed in Fig. 3. After developing the system, it has been tested for many months for verifying the whole functionality in real-time. The use of our methodology resulted in the fault detection accuracy and the lights are automatically ON/OFF which also saved electricity.

In the above figure, the first street light is OFF because of the fault in it. At the point of time, the red color LED will start glowing. In the success case of street light $\mathrm{ON}$ no action is performed. For our experimental purpose, we used basic LEDs in the place of lights.

Fig. 4 describes the message sent to the authorized person from the Twilio account. Damage is the message which we have written as the indication and the URL is fetched using GPS.

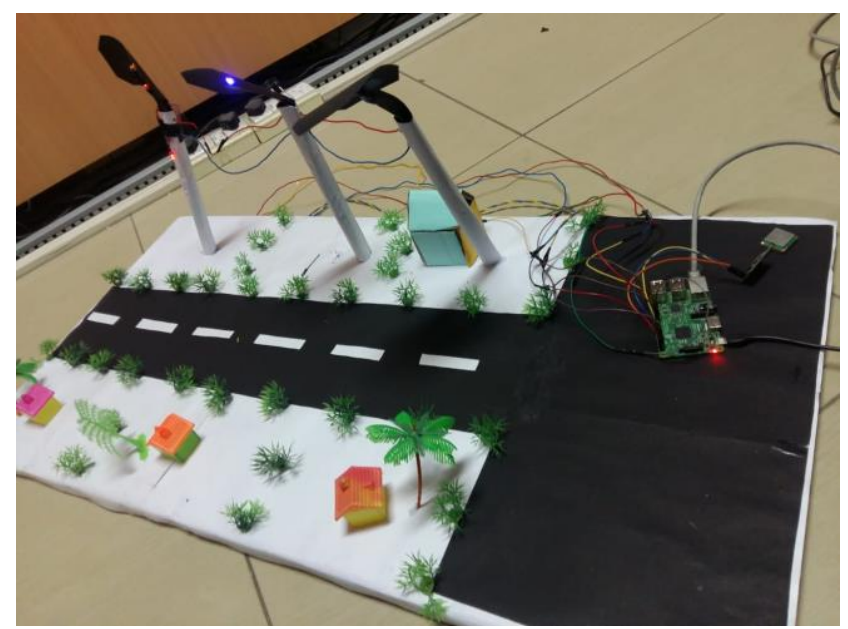

Fig. 3. Overall view of the Research Work.

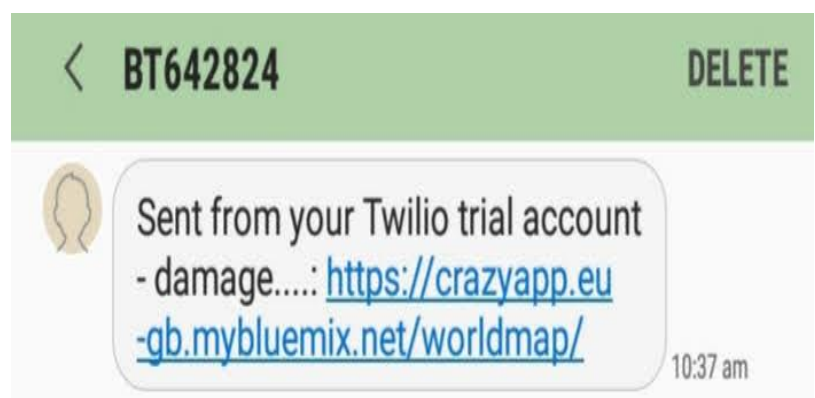

Fig. 4. Output Message from Twilio Account.

Fig. 5 shows the location of the damaged light. The indicator indicates the exact location. In the case of more lights are in one place then the damaged light can be known with the help of a red LED.

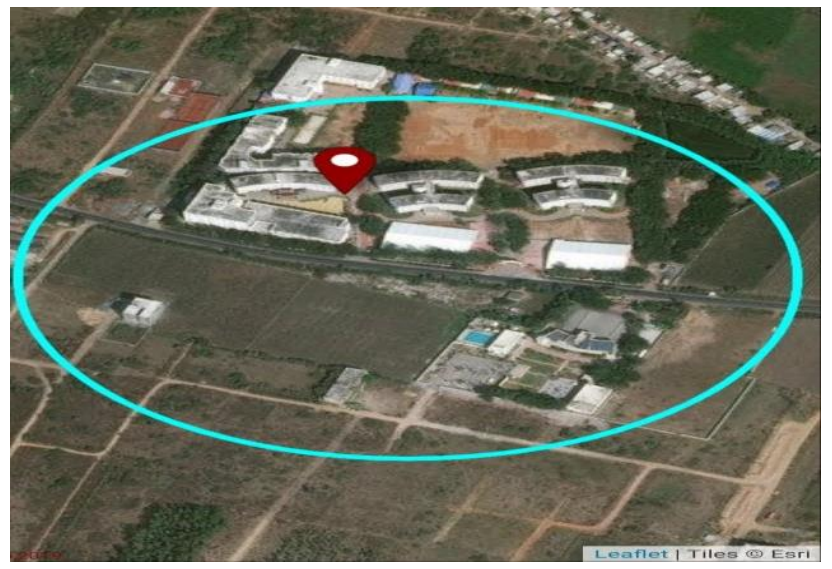

Fig. 5. Damaged Street Light Finding Location.

\section{CONCLUSION}

Nowadays resources (water, power, air, etc.) are very precious. This work focused to protect one such resource i.e. energy. Electricity is one of the major losses of energy. Using IoT the street lights ON/OFF is automated based on the weather condition, the working status of the street light is observed. The LDR sensor senses the environmental changes, the ON/OFF of the street lights is made automatically. 
Whenever the street light got damaged or not on during night time, the LDR sensor senses it and sends the notification to the authorized person that the light is damaged and the location (using GPS) where the light is damaged. It reduces human efforts, delays in fixing the issues. The automatic control of street lights is used to find the exact location when the street light gets damaged. Further, this can be implemented for all the street lamps in rural lamps. Pre-identification of damaged street lights is done based on the expiry of lamps.

\section{ACKNOWLEDGMENT}

We thank all the authors for their outstanding assistances in this paper.

\section{REFERENCES}

[1] International Telecommunication Union.(2005). Internet reports 2005: The internet of things. Geneva: ITU.

[2] Issarny, V., Teixeira, T ., and Hachem, S. and (2011). Ontologies for the internet of things (pp. 1-6). New York: ACM.

[3] Suo, H., Wan, J., Li, F., and Yan, H. (2011). "Advances in cyberphysical systems research", KSII Transactions on Internet and Information Systems, 5(11), 1891-1908.

[4] Vasilakos, V., Lai, C., and Tsai, C.(2014). "Future internet of things: Open issues and challenges". ACM/Springer Wireless Networks.

[5] Morabito, G., Iera, A., \& Atzori, L. and (2010). "The internet of things: A survey," Computer Networks, 54 (15), 2787-2805.doi: https://doi.org/10.1016/j.comnet.2010.05.010.

[6] Miorandi, D., Chlamtac, I., Pellegrini, F. D., and Sicari, S. (2012). "Internet of things: Vision, applications and research challenges", Ad Hoc Networks, 10(7), 1497-1516.

[7] Sayali Arkade, Akshada Mohite, Rutuj, Vikas, "IoT Based Street Lights For Smart City" International Journal for Research in Applied Science \& Engineering Technology (IJRASET), Volume 4 Issue XII, December 2016.

[8] Agar Deo, Sachin Prakash and Asha Patil, "ZigBee-based Intelligent Street Lighting System", 2nd International Conference on Devices, Circuits and Systems (ICDCS), 2014.

[9] S. P. Raja and T. Dhiliphan Rajkumar ,"Internet of Things: Challenges, Issues and Applications", Journal of Circuits, Systems, and Computers Vol. 27, No. 9, 2018, pp. 1-16.

[10] Li, S., Zu, L.D., and He, W., (2014)," Internet of Things in Industries: A Survey" IEEE Transactions on Industrial Informatics, 10(4).doi: 10.1109/TII.2014.2300753.
[11] Atzori, L., Iera, A., Giusto, D., and Morabito, G. (2010). "The Internet of Things", Springer, 2010. ISBN: 978-1-4419-1673-0.

[12] Saifuzzaman, M., Nur, F.N., Moon, N.N., and Khan, A.H. (2017). "Smart Security for an Organization based on IoT", International Journal of Computer Applications 165(10), 33-38.

[13] Sayali Arkade, Akshada Mohite, Rutuj, Vikas, "IoT Based Street Lights For Smart City" International Journal for Research in Applied Science \& Engineering Technology (IJRASET), Volume 4 Issue XII, December 2016.

[14] B.Abinaya, S.Guru Priya, "IOT BASED SMART AND ADAPTIVE LIGHTING IN STREET LIGHTING" Department of Information Technology Sri Sairam Engineering College.

[15] Sindhu.A.M, Jerin George, Sumit Roy, Chandra J, "Smart Streetlight Using IR Sensors" IOSR Journal of Mobile Computing \& Application (IOSR-JMCA) e-ISSN: 2394- 0050, P-ISSN: 2394-0042.Volume 3, Issue 2.

[16] Vaishali Gupta, Krutika Thakur, Ritesh Thakur, "Based Smart Street Lights" International Journal of Research (IJR), Volume 2, Issue 10, October.

[17] Dhingra, V. \& Cho, S. K. (2008). "Street Lighting Control Based on Lon Works Power Line Communication," IEEE In- ternational Symposium on Power Line Communications and Its Applications, Jeju City, 2-4 April 2008, pp. 396- 398.

[18] Amey Manekar, J., Dr. Kshirsagar, Dr. R .V. (2016). ” Design and Implementation of Automatic Street Light Controller for Energy Optimization Using FPGA", International Journal of Advanced Research in Computer and Communication Engineering Vol. 5, Issue 6, June 2016.

[19] Paridhi, Holani., Chaitanya, Amin., Rahul, Kaul., and Ashutosh, Nerkar. (2013). "GSM Based Autonomous Street Illumination System for Efficient Power Management" International Journal of Engineering Trends and Technology-Volume4Issue1.

[20] Sachin Datta, N S., Abdul Latif Saleem., Sachin, H S., Raja Sagar, R., and Usha, M, S. (2015) "Street Light Monitoring and Control System" International Journal of Engineering and Techniques - Volume 1 Issue2.

[21] Monica, Pujari., Rajput, K,Y., Priyanka, Yadav., and Gargeyee, Khatav. (2013) " Intelligent Street Lighting System Using Gsm" International Journal of Engineering Science Invention Volume 2 Issue 3.

[22] Tarun Kumar, B., Sumathi, V., and Krishna Sandeep, A., (2013) "Arm Based Street Lighting System with Fault Detection" International Journal of Engineering and Technology- Vol 5 No 5 Oct-Nov 2013.

[23] Lopes, J.P., deSouza, I.H., Gobbato, C., Denardin, G.W., Kohler, S.V. (2016). "Integrated topology of DC converter for street lighting system based on LED modular drivers", Industry Applications (INDUSCON), 12th IEEE International Conference. 